\title{
Conhecimento sobre Covid-19 dos profissionais de enfermagem atuantes no enfrentamento da doença
}

\author{
Knowledge about Covid-19 of nursing professionals working with the disease \\ Conocimientos sobre Covid-19 de profesionales de enfermería que trabajan con la enfermedad
}

Recebido: 21/08/2021 | Revisado: 15/08/2021 | Aceito: 27/08/2021 | Publicado: 30/08/2021

\author{
Wanmar de Souza Oliveira \\ ORCID: https://orcid.org/0000-0002-7233-4777 \\ Universidade Federal de Rondonópolis, Brasil \\ E-mail: w-anmar@hotmail.com \\ Graciela da Silva Migueis \\ ORCID: https://orcid.org/0000-0001-7287-6026 \\ Universidade Federal de Rondonópolis, Brasil \\ E-mail: graciela.migueis@ufr.edu.br \\ Michele Salles da Silva \\ ORCID: https://orcid.org/0000-0002-4076-5628 \\ Universidade Federal de Rondonópolis, Brasil \\ E-mail: michele.salles@ufr.edu.br \\ Washington Júnio Oliveira \\ ORCID: https://orcid.org/0000-0002-8020-8594 \\ Universidade Federal de Rondonópolis, Brasil \\ E-mail:wasj1oliveira@gmail.com
}

\begin{abstract}
Resumo
A Covid-19 foi detectada em dezembro de 2019, alastrou-se mundialmente, mudando a forma de trabalho das pessoas, em especial aquelas que estão atuando na linha de frente, os profissionais de enfermagem. Estes tiveram que conviver com a situação no ambiente de trabalho e ao mesmo tempo aprender sobre o novo vírus. Nesse contexto, diversos estudos iniciaram a ser produzidos para aprimorar a assistência desses profissionais a pacientes acometidos pela Covid-19 e proporcionar conhecimento aos mesmos. Este estudo teve por objetivo avaliar o conhecimento dos profissionais de enfermagem atuantes no contexto pandêmico sobre as especificidades da Covid-19. Trata-se de um estudo quantitativo, descritivo, transversal, realizado em um hospital em Rondonópolis, MT. Foi realizada análise da confiabilidade por meio do Alfa de Cronbach. A coleta de dados foi por meio de um questionário, tipo checklist. Foram entrevistados 50 profissionais atuantes na linha de frente a Covid-19, sendo 7 enfermeiros e 43 técnicos em enfermagem. O instrumento apresentou alta confiabilidade, de 0,885 . Notou-se que há compreensão sobre aspectos gerais da Covid-19, como forma de infecção, sinais e sintomas, diagnósticos e tratamento. Em síntese, os entrevistados demonstraram conhecimentos pareados com as informações dispostas nas normativas vigentes, servindo de apoio na prestação da assistência.
\end{abstract}

Palavras-chave: Covid-19; Enfermagem; Conhecimento.

\begin{abstract}
Covid-19 was detected in December 2019, spread worldwide, changing the way people work, especially those who are working on the front line, the nursing professionals. They had to live with the situation in the work environment and at the same time learn about the new virus. In this context, several studies began to be produced to improve the care of these professionals to patients affected by Covid-19 and provide knowledge to them. This study aimed to evaluate the knowledge of nursing professionals working in the pandemic context on the specifics of Covid-19. This is a quantitative, descriptive, cross-sectional study conducted in a hospital in Rondonópolis, MT. Reliability analysis was performed using Cronbach's alpha. Data collection was by means of a checklist questionnaire. Fifty professionals working in the front line at Covid-19 were interviewed, being 7 nurses and 43 nursing technicians. The instrument showed high reliability, 0.885. It was noted that there is understanding about general aspects of Covid-19, such as the form of infection, signs and symptoms, diagnosis, and treatment. In summary, the interviewees demonstrated knowledge paired with the information provided in the current regulations, serving as support in the provision of care.
\end{abstract} Keywords: Covid-19; Nursing; Knowledge.

\section{Resumen}

El Covid-19 se detectó en diciembre de 2019, se extendió por todo el mundo, cambiando la forma de trabajar de las personas, especialmente de las que actúan en primera línea, los profesionales de la enfermería. Estos tuvieron que convivir con la situación en el entorno laboral y al mismo tiempo aprender sobre el nuevo virus. En este contexto, se 
empezaron a producir varios estudios para mejorar la atención de estos profesionales a los pacientes afectados por la Covid-19 y proporcionarles conocimientos. Este estudio tiene como objetivo evaluar el conocimiento de los profesionales de la enfermería en el contexto pandémico sobre las especificidades de la Covid-19. Se trata de un estudio cuantitativo, descriptivo y transversal, realizado en un hospital de Rondonópolis, MT. La recopilación de datos se hizo mediante un cuestionario, tipo lista de comprobación. Fueron entrevistados 50 profesionales de la línea de frente a Covid-19, siendo 7 enfermeros y 43 técnicos en enfermería. El instrumento presentó una alta confiabilidad, de 0,885 . Se observa que hay una comprensión de los aspectos generales de la enfermedad, como la forma de infección, los síntomas, el diagnóstico y el tratamiento. En síntesis, los entrevistados demostraron tener conocimientos parejos con las informaciones dispuestas en las normativas vigentes, sirviendo de apoio en la prestación de la asistencia.

Palabras clave: Covid-19; Enfermería; Conocimiento.

\section{Introdução}

O primeiro alerta sobre o novo agente viral que ocasiona uma doença respiratória grave, identificado como Covid-19, ou Coronavírus 2019, foi detectada em dezembro de 2019, na cidade de Wuhan, capital da província da China Central. Rapidamente, esta doença transmitida de pessoa para pessoa, principalmente por vias respiratórias, se disseminou por toda China, alastrando-se para mais de 200 países, o que levou a Organização Mundial da Saúde (OMS) a emitir um alerta sanitário internacional: a Declaração de Emergência em Saúde Pública de Importância Internacional, de 30 de janeiro de 2020 (Silva, 2020).

Após essa Declaração, o Ministério da Saúde (MS), por meio da Portaria n 188 , de 3 de fevereiro de 2020, declarou Emergência em Saúde Pública de Importância Nacional (ESPIN), em decorrência da Infecção Humana pelo novo Coronavírus (2019-nCoV), reconhecendo que a situação demanda o emprego urgente de medidas de prevenção, controle e contenção de riscos, danos e agravos à saúde pública. A complexidade desta situação mobilizou esforço conjunto de todos os serviços da rede de saúde do Sistema Único de Saúde (SUS) para identificação da etiologia e adoção de medidas proporcionais e restritas aos riscos (Brasil, 2020).

A Covid-19 atingiu as pessoas em diferentes níveis de complexidade, sendo os casos mais graves acometidos de uma insuficiência respiratória aguda que requer cuidados hospitalares intensivos, incluindo o uso de ventilação mecânica (CDC, 2020). A facilidade de propagação, a falta de conhecimento sobre o vírus e o aumento exponencial do número de contágios fez com que a OMS elevasse a doença ao status de pandemia em março de 2020 (WHO, 2020).

Os números contabilizados relacionados à pandemia de Covid-19 são alarmantes, com dimensões globais. Até 31 de julho de 2021, a Organização Pan-Americana da Saúde (OPAS) e OMS registraram 196. 995.824 casos de Covid-19 confirmados no mundo e 4.203.926 mortes. Na Região das Américas, 14.449.921 pessoas que foram infectadas pelo novo coronavírus, se recuperaram (OMS, 2021).

No Brasil, segundo OPAS (2021), o primeiro caso da doença foi confirmado em fevereiro de 2020, na cidade de São Paulo-SP, com uma pessoa que havia viajado para o exterior. Rapidamente, outros estados também reportaram casos, fazendo com que os números atingissem patamares elevados num curto período de tempo. Até julho de 2021 registram-se19. 880.273 casos confirmados de Covid-19, com 40.904 novos casos dias e 555.460 mortes.

Segundo a Secretaria de Saúde do Estado de Mato Grosso em novembro de 2020 na região Centro-oeste, o Estado de Goiás destacava-se por ser o mais atingido com o número de casos, são 266.752 confirmados e 5.936 óbitos por Covid-19. Em seguida, o Distrito Federal, com 219,012 casos confirmados e 3.808 óbitos e, ocupando o terceiro ranking, está o estado de Mato Grosso com 486.683 confirmados e 12.541 óbitos.

Em Mato Grosso, dentre os dez municípios com maior número de casos de Covid-19, destacam-se os municípios de Cuiabá (13.958), Várzea Grande (5.234), Rondonópolis (4.001), Lucas do Rio Verde (3.326), Sorriso (3.089), Tangará da Serra (2.772), Sinop (2.357), Primavera do Leste (2.108), Nova Mutum (1.623) e Campo Novo do Parecis (1.271). Ressalta-se 
neste contexto, Rondonópolis, sendo o terceiro município com maior índice de casos confirmados por Covid-19 no Estado. Até outubro de 2020, registrou-se 8.842 casos confirmados, 6.921 recuperados e 284 óbitos (SES-MT, 2020). Já em 31 de julho de 2021, os índices no município de Rondonópolis registraram34. 777 casos confirmados, 32.829 recuperados, 892 óbitos (SESMT, 2021).

Neste sentido, medidas sanitárias de controle do contágio foram e permanecem sendo adotadas para garantir a proteção da população, desacelerar a tendência crescente de transmissão e impedir o colapso dos serviços de saúde (Oliveira et al, 2020). Situação ainda presente nos diversos estados brasileiros.

Diante do panorama, com a população em geral se infectando, alto índice de letalidade, a pandemia da Covid-19 tem causado desconforto à sociedade e, conforme ressalta Souza e Souza (2020) o novo vírus impôs mudanças severas no trabalho de diversos profissionais da saúde, os quais têm atuado de forma incansável nos cuidados aos infectados e na contenção da disseminação do vírus. Dentre estes profissionais, destacamos a enfermagem, que vem atuando no contexto de enfrentamento da pandemia, vivenciando uma situação de incerteza, estresse, muitas vezes com sobrecarga de trabalho, esgotamento mental, cansaço físico, condições de trabalho inadequadas, estando sujeitos cotidianamente ao risco de adoecer pela Covid-19.

Dados registram que na área de enfermagem, 79,38\% de casos confirmados do novo coronavírus entre os trabalhadores ocorreram entre março e dezembro de 2020. Dos 57.615 infectados no País, 45.737 tiveram diagnóstico positivo da doença entre 20 de março a dezembro de 2020. Já em 2021, de janeiro a julho, foram confirmados 11.878 casos da Covid19 entre esses profissionais o total de óbitos na categoria chega a 838 no País (COFEN, 2021).

No estado de MT, $20 \%$ dos enfermeiros e $8,28 \%$ entre técnicos e auxiliares de enfermagem tiveram casos confirmados da Covid-19 (SES, 2020), são 143 profissionais que vieram a óbito. O Brasil destaca-se como o país onde mais morreram enfermeiros no mundo por conta da pandemia (COFEN, 2020).

Face ao exposto, enaltecendo por ser uma doença nova, com escassos estudos, grande risco de contaminação dos profissionais de enfermagem, permeada pela insegurança que ocasiona frente a tantas incertezas, é indiscutível a necessidade de se identificar como se dá o acesso às informações e a construção do conhecimento relacionado ao Covid-19. Tais aspectos nos instigaram e levaram aos seguintes questionamentos: Qual o conhecimento que os profissionais de enfermagem atuantes na assistência ao enfrentamento da pandemia possuem acerca do Covid-19? Os profissionais de enfermagem utilizam a implementação de medidas de precauções para o atendimento ao paciente com Covid-19?

Pesquisas que abordem o conhecimento dos profissionais de enfermagem sobre o Covid-19 ainda são incipientes, e carece de investigação que explorem de maneira mais aprofundada com o intuito de produzir um conhecimento e elucidar informações que ainda são preliminares. Assim, com o propósito de responder a alguns dos questionamentos, fomos desafiados a realizar a presente pesquisa que possui o objetivo de avaliar o conhecimento dos profissionais de enfermagem atuantes no contexto pandêmico sobre as especificidades da Covid-19.

\section{Metodologia}

Trata-se de um estudo quantitativo, descritivo, do tipo transversal, realizado um hospital filantrópico do município de Rondonópolis, Mato Grosso. A pesquisa quantitativa é uma modalidade de pesquisa que atua sobre um problema humano ou social, é baseada no teste de uma teoria e composta por variáveis quantificadas em números, as quais são analisadas de modo estatístico, com o objetivo de determinar se as generalizações previstas na teoria se sustentam ou não (Knechtel, 2014).

Diante da pandemia instaurada mundialmente, o hospital se tornou referência para o atendimento a pacientes acometidos por Covid-19, e assim alguns setores de assistência ao paciente foram reorganizados para o atendimento prioritário para essa biocenose. Nesse sentido, optou-se pela realização do estudo no referido hospital. Além disso, é campo de atividades práticas de ensino para diversos cursos e Instituições locais, de nível médio, superior e pós-graduação. 
Os locais selecionados para a realização da pesquisa no hospital em questão foram os setores de assistência exclusivos à pacientes acometidos por Covid-19, sendo: Unidade de Terapia Intensiva Geral, Unidade de Terapia Intensiva Covid-19 e Ala Covid-19. A biocenose do estudo foi composta pelos profissionais de enfermagem do hospital de estudo, e a amostra por todos os profissionais que estavam na linha de frente ao atendimento de pacientes com Covid-19 das três unidades de internação: Unidade de Terapia Intensiva Geral, Unidade de Terapia Intensiva Covid-19 e Ala Covid-19 e, que se enquadraram nos critérios de inclusão e exclusão pré-estabelecidos.

Os critérios de inclusão foram: ser profissional de enfermagem com vínculo empregatício com a Instituição hospitalar; estar lotado em uma das unidades de assistência ao paciente com Covid-19; prestar assistência direta aos pacientes com Covid19 e ser maior de idade. Foram considerados inelegíveis para a participação da pesquisa, os profissionais que estavam no período de férias, licença saúde ou ausente do setor após três tentativas de contato no decorrer da coleta de dados, portanto, excluídos da coleta.

Após a identificação do participante da pesquisa foi esclarecido o objetivo e agendado data e horário para aplicação do questionário. Este fora realizado após assinatura do Termo de Consentimento Livre e Esclarecido (TCLE), assinado em duas vias, uma para o pesquisador e outra para o participante.

A coleta de dados ocorreu entre os meses de agosto de 2020 a janeiro de 2021 por meio de um questionário estruturado, do tipo checklist, dividido em duas partes. A primeira com aspectos para a caracterização dos participantes e a segunda contempla tópicos referentes ao conhecimento sobre Covid-19.

Os dados foram coletados pelo pesquisador, de maneira presencial e individual com cada participante, em um ambiente confortável, livre de ruídos, no período de turno de trabalho (diurno e noturno) dos colaboradores da Instituição, com tempo médio de aproximadamente 20 minutos, sem que alterasse na rotina de trabalho. Foram respeitados todos os preceitos éticos e legais.

Ressalta-se que antes do início da coleta dos dados foi realizado teste piloto para validação do instrumento. A análise da testagem mostrou que as pessoas entenderam as perguntas do questionário não sendo necessário modificá-la.

O instrumento de coleta foi submetido à análise da confiabilidade, realizada por meio da avaliação da consistência interna utilizando o Coeficiente de Alfa de Cronbach. Este coeficiente mede a correlação entre as respostas em um questionário por meio da análise do perfil das respostas dadas pelos respondentes cujos valores variam de 0 a 1 (Cunha, Almeida Neto e Stackfleth, 2016; Gottems et al 2018; Landis e Koch, 1977). A classificação da Confiabilidade a partir do cálculo do coeficiente Alfa de Cronbach de acordo com seus limites é: Pequena ( $\alpha>0,0-0,21)$, Razoável $(\alpha>0,21-0,40)$, Moderada ( $\alpha>0,41-0,60)$, Substancial ( $\alpha>0,61-0,80)$, Quase perfeita ( $\alpha>0,81-1,00)$. Quanto o valor se aproxima de 1, significa maior confiabilidade entre os indicadores (Landis e Koch, 1977).

De porte às informações obtidas, os dados foram organizados em uma planilha eletrônica do programa Microsoft Office Excel® e calculadas frequências absolutas e relativas. Posteriormente foram analisadas mediante estatística descritiva e apresentados por meio de gráficos e/ou tabelas.

Este estudo é um recorte do projeto de pesquisa matricial intitulada "Eventos associados à pandemia do coronavírus em um hospital público do município de Rondonópolis/MT, na perspectiva da equipe de enfermagem" e desenvolvida no Programa de Residência Multiprofissional em Saúde do Adulto e Idoso. Foi submetido à apreciação do Comitê de Ética e Pesquisa em Seres Humanos e recebeu parecer favorável sob n. CAAE 33496120.1.0000.8088. 


\section{Resultados}

A análise da consistência interna do instrumento por meio do Coeficiente Alfa de Cronbach apresentou resultado de0, 885. Esse resultado demonstra que o questionário aplicado possui uma consistência interna quase perfeita ou confiabilidade alta.

Foram entrevistados 50 profissionais da área da enfermagem, 07 (14\%) são enfermeiros e 43 (86\%) são técnicos de enfermagem. A prevalência dos participantes é do sexo feminino, 44 (88\%), e apenas 06 (12\%) de sexo masculino, e possuem idade variável entre 22 e 55 anos, sendo o maior número de profissionais com idade de 34 a 39 anos (34\%). Esta caracterização da população de estudo e demais aspectos relacionados como: estado civil, escolaridade, setor de atuação ao enfrentamento da Covid-19, tempo de formação profissional na área, tempo de experiência profissional e se possui outro vínculo empregatício podem ser observados no Quadro 1.

Quadro 1: Caracterização dos profissionais de enfermagem atuantes no atendimento a Covid-19. Rondonópolis, MT, Brasil, 2021.

\begin{tabular}{|c|c|c|}
\hline SEXO & $\mathbf{N}(\mathbf{5 0})$ & $\%$ \\
\hline $\begin{array}{l}\text { Feminino } \\
\text { Masculino }\end{array}$ & $\begin{array}{c}44 \\
6\end{array}$ & $\begin{array}{l}88 \\
12\end{array}$ \\
\hline IDADE & $\mathbf{N}(\mathbf{5 0})$ & $\%$ \\
\hline $\begin{array}{l}22-27 \\
28-33 \\
34-39 \\
40-45 \\
46-55\end{array}$ & $\begin{array}{c}6 \\
15 \\
17 \\
4 \\
8\end{array}$ & $\begin{array}{c}12 \\
30 \\
34 \\
8 \\
16\end{array}$ \\
\hline ESTADO CIVIL & $\mathbf{N}(\mathbf{5 0})$ & $\%$ \\
\hline $\begin{array}{l}\text { Casado } \\
\text { Solteiro } \\
\text { Divorciado } \\
\text { Viúvo }\end{array}$ & $\begin{array}{c}24 \\
23 \\
2 \\
1\end{array}$ & $\begin{array}{c}48 \\
46 \\
4 \\
2\end{array}$ \\
\hline ESCOLARIDADE & $\mathbf{N}(\mathbf{5 0})$ & $\%$ \\
\hline $\begin{array}{l}\text { Pós-graduação } \\
\text { Superior completo } \\
\text { Superior incompleto } \\
\text { Ensino médio completo } \\
\text { Ensino médio incompleto }\end{array}$ & $\begin{array}{c}8 \\
5 \\
8 \\
29 \\
0 \\
\end{array}$ & $\begin{array}{c}16 \\
10 \\
16 \\
58 \\
0\end{array}$ \\
\hline CATEGORIA PROFISSIONAL & $\mathbf{N}(\mathbf{5 0})$ & $\%$ \\
\hline $\begin{array}{l}\text { Técnico de enfermagem } \\
\text { Enfermeiro }\end{array}$ & $\begin{array}{l}43 \\
07\end{array}$ & $\begin{array}{l}86 \\
14\end{array}$ \\
\hline SETOR DE ATUAÇÃO & $\mathbf{N}(\mathbf{5 0})$ & $\%$ \\
\hline $\begin{array}{l}\text { UTI Covid } \\
\text { UTI Geral } \\
\text { Enfermaria Covid }\end{array}$ & $\begin{array}{l}22 \\
12 \\
16\end{array}$ & $\begin{array}{l}44 \\
24 \\
32\end{array}$ \\
\hline TEMPO DE FORMAÇÃO & $\mathbf{N}(\mathbf{5 0})$ & $\%$ \\
\hline $\begin{array}{l}<6 \mathrm{M} \\
6 \mathrm{M}-1 \mathrm{~A} \\
1-2 \mathrm{~A} \\
2-3 \mathrm{~A} \\
4-5 \mathrm{~A} \\
>5 \mathrm{~A}\end{array}$ & $\begin{array}{c}9 \\
4 \\
6 \\
9 \\
4 \\
18\end{array}$ & $\begin{array}{c}18 \\
8 \\
12 \\
18 \\
8 \\
36\end{array}$ \\
\hline
\end{tabular}




\begin{tabular}{|l|c|c|}
\hline TEMPO DE EXPERIÊNCIA & N (50) & \% \\
\hline < 6 M & 12 & 24 \\
6 M - 1 A & 4 & 8 \\
1 - $\mathbf{A}$ & 5 & 10 \\
2 - 3 A & 8 & 16 \\
4 - 5 A & 4 & 8 \\
> 5 A & 17 & 34 \\
\hline OUTRO VINCULO EMPREGATÍCIO & $\mathbf{N}(\mathbf{5 0})$ & \% \\
\hline SIM & 24 & 48 \\
Ñ̃O & 26 & 52 \\
\hline
\end{tabular}

Fonte: Dados da pesquisa (2021).

Nota-se em relação ao estado civil, duas categorias que explicitam maior porcentagem sendo, $48 \%$ casados, seguidos com $46 \%$ de solteiros. Uma parcela dos entrevistados, 16\% possuem pós-graduação e 36\% com mais de 5 anos de formação.

Em referência ao conhecimento teórico dos profissionais de enfermagem sobre o significado da Covid-19, 100\% deles responderam compreensão sobre a doença. Os aspectos relacionados à Covid-19 e perguntados aos participantes é demonstrado na Tabela 1, a seguir.

Tabela 1: Aspectos relacionados à Covid-19 e o número de citação sobre o referido tópico. Rondonópolis, MT, Brasil, 2021.

\begin{tabular}{lc}
\hline ASPECTOS RELACIONADOS À COVID-19 & N $^{\mathbf{0}}$. DE CITAÇÃO \\
\hline Forma de transmissão & 254 \\
Sinais e sintomas & 512 \\
Diagnóstico & 264 \\
Medidas protetivas & 254 \\
TOTAL DE CITAÇÕES & 1.284 \\
\hline
\end{tabular}

Fonte: Dados da pesquisa (2021).

Vários aspectos sobre a Covid-19 foram abordados como: à forma de transmissão, conhecimento sobre os sinais e sintomas, a respeito da forma de realização do diagnóstico e das medidas protetivas conhecidas e utilizadas pelos entrevistados. Cada aspecto elencado foi investigado com detalhes junto ao participante e houve as seguintes citações: forma de transmissão (254 citações), sinais e sintomas (512 citações), quanto ao diagnóstico (264 citações) e medidas protetivas conhecidas e utilizadas pelos entrevistados (254 citações), conforme apresentado na Tabela 1.

Além disso, foram indagados quanto aos meios de informação aos quais estes profissionais tiveram acesso sobre a patologia e houve 111 citações. As citações se referem às seguintes formas: internet, televisão, capacitação no ambiente de trabalho, leitura de artigos científicos, pesquisa divulgada na mídia e com a própria rotina de trabalho. No Gráfico 1, em seguida, observa-se a relação de conhecimento dos entrevistados entre as formas de transmissão e a forma de aprendizado sobre o Covid-19. 
Gráfico 1: Formas de transmissão e relação com a forma de aprendizado. Rondonópolis, MT, Brasil, 2021.

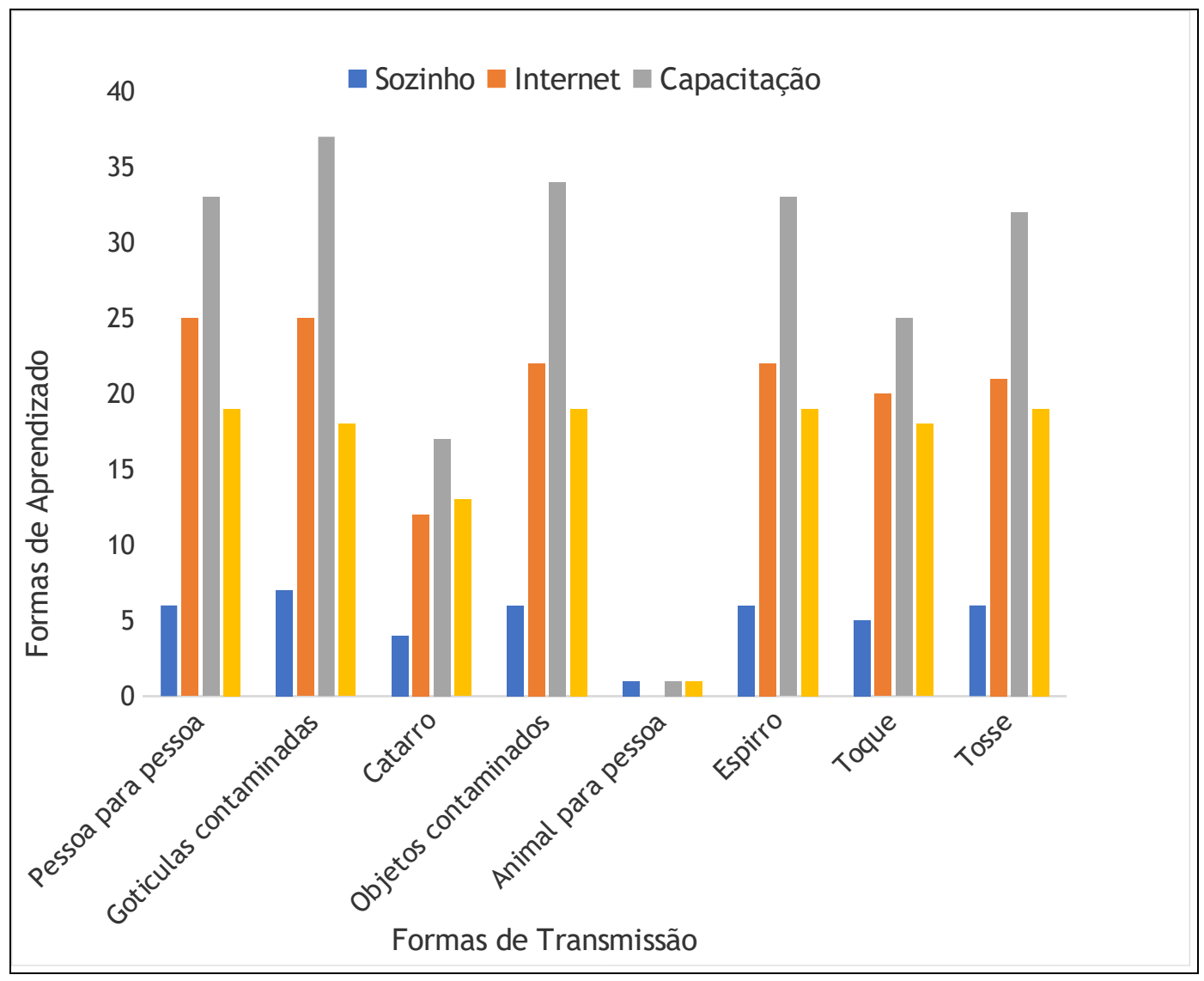

Fonte: Dados da pesquisa (2021).

O gráfico acima observa-se o detalhamento das formas de transmissão e a relação com a forma de aprendizado. A forma de transmissão de Covid-19 mais citada pelos entrevistados foi por gotículas (44) e maneira de aprendizado de maior citação referente a essa transmissão, foi a capacitação (37), seguida de internet (25) e TV (18). O segundo modo de transmissão mais citado foi por objetos contaminados (40) e a forma de aprendizado mais expressiva dessa transmissão também foi capacitação (39), internet (22) e TV (19). Destaca-se a disseminação pessoa a pessoa (39), em terceira posição de citação, juntamente pela contaminação por espirro (39), e ambas apresentam semelhanças nas formas de aprendizado, sendo capacitação (34 para disseminação pessoa a pessoa $/ 33$ para contaminação por espirro), internet (25/22) e TV (18/16), respectivamente.

Sobre os sinais e sintomas da Covid-19 foram identificadas 512 citações. A dificuldade respiratória foi a mais expressiva (50 citações), seguido de cansaço (48), febre (47), alteração de paladar (46), perda de olfato (46), cefaléia (46), tosse (44), dor de garganta (39), coriza (38), dispnéia (37), disfunção gastrointestinal (36) e redução do apetite (35).

No que se refere à confirmação do diagnóstico, houve diversas citações, sendo respectivamente: laboratorial RT- PCR (Reverse Transcription Polymerase Chain Reaction) (42 citações), clinico- imagem com (40 citações), clinico- epidemiológico (29 citações) e clinico (23 citações). Quando questionados sobre o tempo de confirmação de cada diagnóstico clinico e imunológico os valores das citações foram respectivamente: $8^{\circ}$ ao $14^{\circ}$ dia (21 citações), até o $8^{\circ}$ dia (18), em qualquer momento (02), não soube responder (01), $8^{\circ}$ ao $14^{\circ}$ dia (28), até o $8^{\circ}$ dia (08), em qualquer momento (08), não soube responder (00), totalizando assim 264 citações.

Ao constatar o conhecimento sobre as recomendações existentes de medidas protetivas para Covid-19, foram destacadas 254 citações, como retrata o Gráfico 2 abaixo. 
Gráfico 2: Conhecimento sobre medidas protetivas para Covid-19 e as medidas protetivas utilizadas na assistência. Rondonópolis, MT, Brasil, 2021.

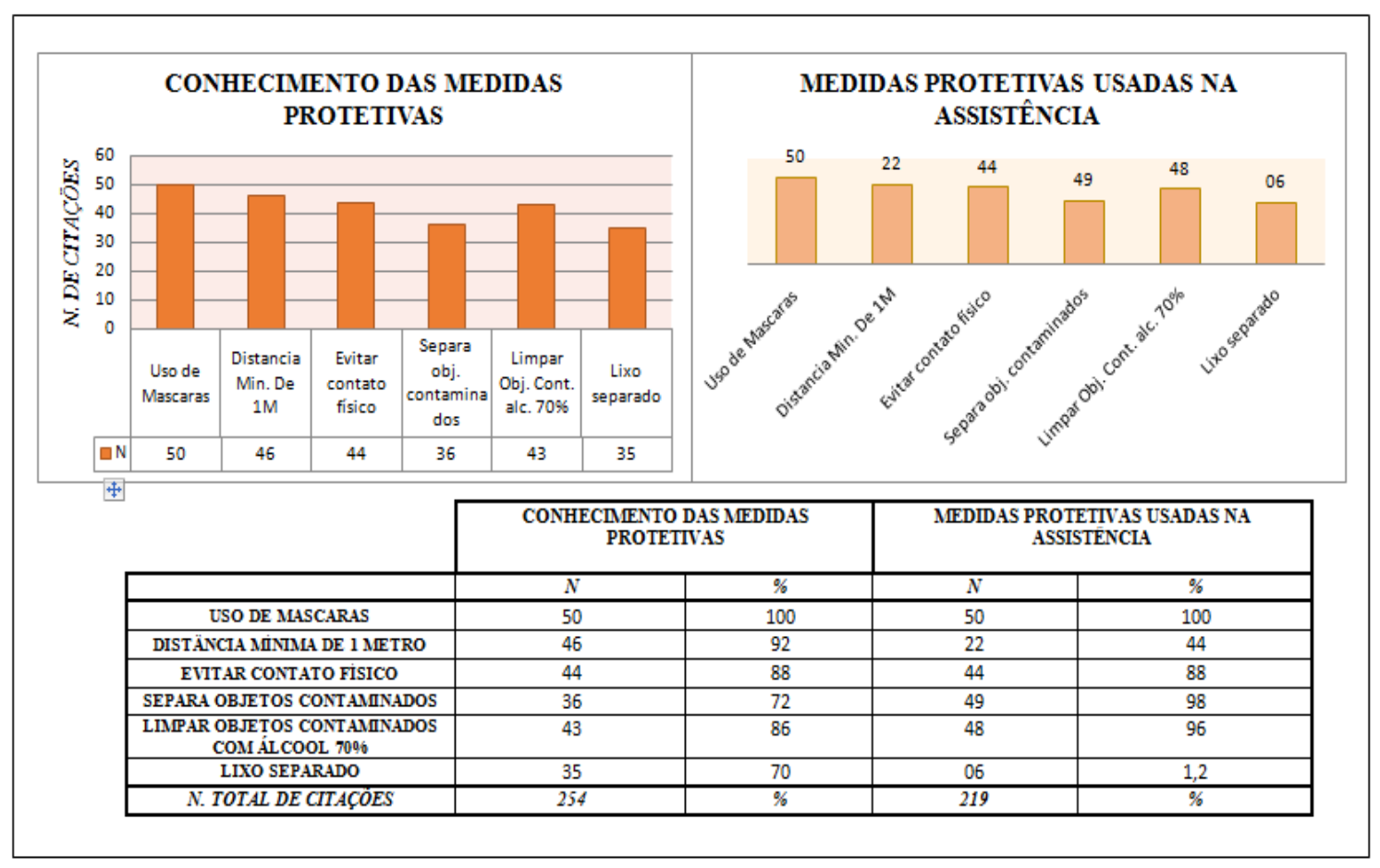

Fonte: Dados da pesquisa (2021).

O gráfico acima destaca informações importantes em que todos os entrevistados reconhecem o uso de máscara facial (100\%) como medida protetiva. Um elevado percentual (92\%), também admitiu como medida protetiva o distanciamento mínimo de 1 metro, contudo22 (44\%) entrevistados a realizam durante no serviço. Em seguida, a medida de proteção mais citada que os participantes conhecem é evitar o contato físico (88\%) e limpeza/desinfecção (86\%) de objetos contaminados com álcool a 70\%. Das medidas mais utilizadas durante a assistência, além do uso de máscara, destaca-se com $98 \%$ a separação de objetos contaminados, $96 \%$ a limpeza/desinfecção dos objetos com álcool a $70 \%$.

Ademais, foram indagados sobre medidas consideradas de prevenção para a Covid-19 e 37 (74\%) relataram o uso de Equipamentos de Proteção Individual (EPIs) como a principal.

\section{Discussão}

A escolha do melhor método de avaliação da confiabilidade deve ser feita de forma criteriosa, levando em conta, sobretudo, as características do instrumento, a população avaliada e o tipo e nível de mensuração dos dados gerados. Os principais métodos de avaliação da confiabilidade são os baseados na correlação entre os itens e na consistência interna. Ao se avaliar a confiabilidade, há necessidade de que os instrumentos de medida apresentem altos níveis de qualidade (Cunha, Neto e Stackfleth, 2016).

Nesse estudo, o resultado do coeficiente alfa de correlação apresentado demonstrou uma confiabilidade alta, com resultado de 0,885 . Este resultado indica que houve uma consistência interna do instrumento, sendo, portanto, utilizado na pesquisa.

Nos dias atuais, informações e conhecimentos científicos a respeito da patologia Covid-19 estão sendo realizadas em todos os lugares do mundo. De natureza semelhante, muitos esforços estão sendo despendidos em todo o Brasil para respaldar os profissionais de saúde que atuam na linha de combate na pandemia. 
Os dados neste estudo em relação aos participantes mostram que a grande maioria, 44respondentes, são mulheres, correspondendo a 88\%. A enfermagem ainda é predominantemente composta pelo gênero feminino, isso se deve segundo Silva (2017) ao reflexo da condição histórico e sociocultural que a profissão tem carregado através dos séculos. Este dado foi corroborado com os achados de Gomes et al (2020), em estudo sobre o perfil dos profissionais de enfermagem que estão atuando durante a pandemia do novo coronavírus, retratando $86 \%$ dos participantes do sexo feminino.

Quanto à formação profissional, houve predomínio de técnicos de enfermagem, 43 participantes, equivalendo a 86\%. Este dado confirma com diversos estudos, assim como com os dados do Conselho Federal de Enfermagem (COFEN) divulgados em junho de 2021 onde pontua que há uma maior proporção de técnicos de enfermagem no Brasil em relação a demais profissionais como enfermeiros, sendo 1.464 .308 e 220.217, respectivamente.

Ainda conforme a Resolução COFEN n. 543/2017 o cuidado de enfermagem está diretamente relacionado com a segurança e qualidade da assistência ao paciente, nesse sentido a Resolução trata sobre dimensionar o quantitativo de profissionais das diferentes categorias de enfermagem para os serviços/locais em que são realizadas atividades de enfermagem. Neste raciocínio, a relação de técnicos ocupa um quantitativo superior à de enfermeiros na assistência prestada.

A compreensão acerca do Covid-19 está evoluindo de maneira exponencial em nosso país, uma vez que há diversas orientações provisórias publicadas pela Organização Mundial da Saúde e pelos Centros dos Estados Unidos para Controle e Prevenção de Doenças (Brasil, 2020). Neste sentido, os dados obtidos no estudo demonstram que a totalidade dos entrevistados discorrem saber o significado de Covid-19. Semelhantemente, expressaram conhecer os aspectos gerais da doença, como forma de transmissão, sinais e sintomas, diagnósticos e medidas protetivas.

A importância em ter conhecimento sobre o que é Covid-19 possibilita compreender sobre seus aspectos, como sua forma de transmissão e atuar com a intenção de não propagar o vírus. Diante das citações foi possível evidenciar que os participantes possuem conhecimento acerca da forma de transmissão da Covid-19, uma vez que houveram 254 citações, entre gotículas (44 citações), objetos contaminados (40 citações), espirro e pessoa para pessoa (39 citações), tosse (38 citações), toque nas mãos contaminadas (30 citações), catarro (21 citações) e animal para pessoa (03 citações).

Conforme Brasil (2021), o vírus se propaga por intermédio de gotículas de saliva; espirro; tosse; catarro; contato pessoal próximo, como toque ou aperto de mão; contato com objetos ou superfícies contaminadas, seguido de contato com a boca, nariz ou olhos. Nessa conjuntura, infere-se que os entrevistados possuem conhecimento e está de acordo com o preconizado na literatura, uma vez que a maioria referiu que a transmissão da doença ocorre por intermédio de gotículas expelidas pelos indivíduos contaminados ao falar, espirrar ou tossir, assim como por objetos contaminados e toque nas mãos.

Ao se identificar as formas de aprendizado sobre o Covid-19, se sozinho, por capacitação, busca na internet e pela TV, o modo de aprendizado destacado foi a capacitação em serviço (43 citações), seguido por mídias sociais internet (28 citações) e TV (21 citações). Segundo Arnemann et al (2018), a educação permanente visa capacitar os colaboradores no ambiente hospitalar, e a base é o aprendizado significativo fundamentado nas vivencias dos sujeitos envolvidos, com foco na transformação da prática profissional. Nesse sentido, nota-se que a instituição mesmo adaptando-se aos cuidados em meio à pandemia pode cumprir com seu papel social na formação de seus colaboradores, instruindo-os. Corroborando com Arnemann et al (2018), a educação permanente é uma estratégia capaz de contribuir positivamente na qualidade dos serviços prestados.

Foi possível comparar cada forma de aprendizado relacionando-o a forma de transmissão da Covid-19. Esta analise mostrou que há uma relação diretamente proporcional em cada forma de transmissão com o aprendizado por capacitação, seguida de internet e TV. Para Wang et al, (2021) a internet torna as informações sobre Covid-19 mais acessíveis, especialmente para aqueles que ficam em casa devido à pandemia, sendo sites de organizações oficiais de saúde pública a fonte de informação online mais confiáveis para conhecer sobre a doença e como evitá-la. 
Em contrapartida, foi possível evidenciar um déficit de conhecimento em alguns participantes da pesquisa, de modo que há profissionais na assistência (7,62\%) que discorreram que animais transmitem a Covid-19 para os seres humanos. De acordo com Brasil (2021), não há comprovações cientificas acerca da transmissão do Covid-19 de animais para pessoas. Ainda, a Organização Mundial da Saúde (OMS), a Organização Mundial para a Saúde Animal (OIE), a Associação Mundial de Veterinários para Animais de Estimação (WSAVA) em 2020, apontaram que não há evidências científicas de que os animais de estimação sejam fonte de infecção. Tais divulgações externaram que não há evidências de que os cães possam ser infectados e existem poucos relatos de que gatos parecem ter sido infectados pelo vírus (Brasil, 2021).

Um dos indícios do déficit de conhecimento em relação ao modo de transmissão da Covid-19 pode estar relacionado ao pouco tempo disponível para se apropriar do conhecimento. Circunstância esta, associada ao fato de que alguns participantes possuem mais de um emprego, situação costumeira na enfermagem para se manter financeiramente, e estão sempre ocupados com as atividades no serviço que por muitas vezes é árduo e requer atenção, além das atividades diárias com a rotina de casa e família.

É inegável também que duplas jornadas de trabalho podem ocasionar cansaço físico dos trabalhadores, podendo levar à diminuição da qualidade da assistência prestada, à ocorrência de iatrogenias e estagnação na busca de conhecimento. Destacam Ribeiro et al (2020), que os próprios profissionais de saúde estão sendo desafiados a buscar conhecimento ao mesmo tempo em que atendem aos casos de Covid-19 que sobrecarregam os serviços e realizam o acompanhamento de pacientes com outros problemas de saúde, principalmente doenças crônicas.

Quando indagados sobre os sinais e sintomas da Covid-19, os participantes da pesquisa souberam explicitar a maneira correta, sendo expressivo o número de indicações destes, com 512 citações. O maior indicio de sinais e sintomas relacionados à Covid-19foi a dificuldade respiratória, na qual todos os entrevistados referenciaram. Ainda com mais de 45 citações, destacase também o cansaço físico, a febre, a alteração do paladar, a perda de olfato e a cefaléia. Demais sintomas com abaixo de 45 citações foram a tosse, dor de garganta, coriza, dispnéia, disfunção gastrointestinal e redução do apetite. Apoiado pela OMS (2021), os sintomas podem variar de um resfriado, a uma síndrome gripal, caracterizado por, pelo menos dois dos seguintes sintomas: tosse, febre, coriza, dor de garganta, anosmia, ageusia, distúrbios gastrintestinais, astenia, hiporexia e dispnéia.

A OPAS (2020) discursa que os sintomas mais comuns da Covid-19 são: febre, cansaço e tosse seca. Alguns pacientes podem apresentar dores, congestão nasal, dor de cabeça, conjuntivite, dor de garganta, diarréia, perda de paladar ou olfato, erupção cutânea na pele ou descoloração dos dedos das mãos ou dos pés. Esses sintomas geralmente são leves e começam gradualmente. Neste contexto é possível inferir que os profissionais possuem conhecimento cientifico acerca dos sinais e sintomas da Covid-19, de modo que eles alinharam esses aspectos da doença de acordo com a literatura e informações atuais.

Quanto ao conhecimento dos profissionais a respeito do diagnóstico para a Covid-19 foi constatado que eles possuem conhecimento pareado à literatura atual, uma vez que houveram 42 citações para a realização do exame laboratorial por meio do teste de biologia molecular RT- PCR. É um método preponderante no diagnóstico da Covid-19 por detectar o material genético do SARS-CoV-2 (Chanet et al, 2020). Possui como uma de suas principais características a precisão, e sua recomendação é utilizar amostras do trato respiratório, visto que o vírus apresenta afinidade com células do sistema respiratório (Neto et al, 2021).

Quanto ao período de realização do exame os participantes expressam conhecimentos parcialmente conforme as notas informativas atuais, uma vez que os mesmos explicitam que o tempo de coleta pode variar entre o oitavo e o décimo quarto dia, sendo essa opção citada 21 vezes para teste RT- PCR e 28 vezes para o teste imunológico. A detecção de antígeno (AgTDRs) é um exame imunológico que detecta a presença da proteína do nucleocapsídeo viral do SARS-CoV-2 no organismo por meio da imunocromatografia. Segundo a Nota Técnica publicada em 2021, a coleta pode ser realizada até o $10^{\circ}$ dia de início dos sintomas, sendo preferencialmente entre o $3^{\circ}$ e $7^{\circ}$ dia do início dos sintomas e de acordo com a OPAS (2020), de 
preferência, dentro de 5-8 dias do início dos sintomas, uma vez que devem ser priorizados para pacientes sintomáticos, e eventualmente em contatos de pacientes confirmados em determinadas situações (ambientes fechados ou domicílios) em que indivíduos de alto risco possam ser infectados.

Além disso, foi possível evidenciar que os entrevistados possuem conhecimento quanto às medidas protetivas para evitar a contaminação por Covid-19, sendo citados os meios para prevenção e proteção. Foi unanimidade o uso de máscara facial seja a cirúrgica, PFF (Peça Facial Filtrante) e/ou N95 (máscara de proteção respiratória com alta filtragem), além disso, está a depender do procedimento a ser realizado, condição necessária haja vista os inúmeros procedimentos que a enfermagem executa e alguns são geradores de aerossóis.

Medidas de precaução por contato, gotícula e aerossóis vêm sendo incentivadas por órgãos mundiais de saúde que determinaram a exigibilidade do uso de EPI durante o contato dos profissionais de saúde com pacientes da Covid-19. Estudos iniciais ao surto deixaram evidente a eficácia e o incentivo para a utilização, por exemplo, da máscara N95 (Garcia et al, 2021).

Segurado nas recomendações da OMS (2020), o uso de máscaras é parte de um conjunto completo de medidas de prevenção e controle cujo objetivo é frear a propagação da Covid-19. Recomenda que os profissionais de saúde que atendem casos suspeitos ou confirmados de Covid-19 usem máscara cirúrgica, padrão N95 ou PFF2/ PFF3 nas diversidades de procedimentos existentes, priorizando procedimentos que gerem aerossóis.

Ademais os entrevistados citaram como medida de proteção a Covid-19 o distanciamento mínimo de 01 metro, evitar contato físico, a separação de objetos contaminados, realização de limpeza de objetos contaminados com álcool $70 \%$ e a separação do lixo contaminado. Dentre as medidas preventivas na assistência ao paciente com Covid-19, Brasil (2020) assegura o uso rigoroso das precauções padrão, que incluem a higienização das mãos com água e sabão e álcool 70\%, uso adequado de EPI (máscara cirúrgica, PFF ou N95, luva, touca, macacão e face shield). O texto menciona também medidas de retirada, armazenamento e descarte, além do descarte adequado de material perfurocortante e banho após o plantão.

Considera-se que, além do uso adequado de EPI, a organização do trabalho, o estabelecimento de fluxo de pessoas, o uso de protocolos, são essenciais para a proteção dos profissionais de saúde e dos pacientes (Garcia et al, 2021). Contudo, reitera-se que o conhecimento dos profissionais apresentados aqui acerca da temática atual retrata a responsabilidade profissional, social e cientifica destes no consumo das publicações e a necessidade de se manter atualizado frente à evolução da pandemia.

Por fim como limitação deste estudo podemos apontar que foi desenvolvida em um hospital, apontando a realidade vivida, assim outros locais podem ter realidade distinta ou corroborar com esta. Outra limitação expressiva foi à rapidez das mudanças e informações acerca da Covid-19, uma vez que os estudos científicos ainda são incipientes para a realização do embasamento teórico.

Vale ressaltar que Cardoso et al (2021) explicitam que o novo coronavírus sofre mutações, alertando mais ainda, que a comunidade cientifica e autoridades em saúde devem priorizar o investimento em pesquisas, genética e formulações de vacinas, evitando o estrangulamento do sistema de saúde, que não comporta o grande número de pacientes acometidos pela patologia, proporcionando assim conhecimento, atualizações e barreiras para a evolução da mesma. Assim, incentivamos que pesquisas sejam realizadas, em especial de campo, para contribuir com a comunidade cientifica e geral.

\section{Conclusão}

Diante dos aspectos analisados é possível concluir que os profissionais de enfermagem pesquisados possuem conhecimento acerca da Covid-19, sendo expressivo o alinhamento dos mesmos com a literatura atual, de modo que os mesmos expressam saber o significado de Covid-19, os aspectos gerais da doença, como sua forma de transmissão, sinais e sintomas, diagnósticos e medidas de proteção. 
A forma de transmissão mais citada foi por gotículas, procedimentos que produzem aerolização. A dificuldade respiratória é o sintoma mais expressivo pelos entrevistados, como também o cansaço físico, febre, alteração do paladar, perda de olfato, cefaléia e outros.

Para a realização do diagnóstico laboratorial, o exame por meio do teste de biologia molecular RT- PCR foi o mais citado. E quanto às medidas protetivas contra Covid-19, o uso de EPI como de máscaras (cirúrgicas, PFF2 e/ou N95) conforme o procedimento a ser realizado foram citados de modo significativo. Em relação ao meio de aprendizado, o mais destacado foi a capacitação em serviço.

Por mais que a pesquisa revelou que os profissionais da enfermagem possuem conhecimento a respeito da Covid-19, no geral, ainda há incertezas quanto à mesma, tendo em vista que é uma doença nova, em constante mutação e várias variantes identificadas. Além disso, outras podem surgir, assim sempre haverá a necessidade de atualização e busca de conhecimento.

Em síntese pesquisas estão sendo realizadas, contudo são incipientes, assim destacamos a necessidade de pesquisas de campo como esta que retratem a realidade local dos profissionais. Estas possibilitam dar visibilidade quanto ao conhecimento da equipe, relacionar realidades e propor ações que possam trazer segurança e qualidade na assistência prestada, contribuindo assim com a comunidade cientifica e geral.

Para finalizar é indispensável à realização de trabalhos futuros que abordem as variantes existentes da Covid-19 e suas particularidades, assim como o conhecimento por profissionais da assistência atuantes na linha de frente dessa doença altamente mutável. Ainda, aquelas que abordem as questões biopsicossocioespirituais que permeiam a temática Covid-19.

\section{Referências}

ANVISA. (2020). Nota técnica GVIMS/GGTES/ANVISA nº 04/2020. Orientações para serviços de saúde: medidas de prevenção e controle que devem ser adotadas durante a assistência aos casos suspeitos ou confirmados de infecção pelo novo coronavírus (SARs-Cov-2). Agência Nacional de Vigilância Sanitária (ANVISA). http://portal.anvisa.gov.br/.

ANVISA. (2020). Nota Técnica n 0 04/2020. Orientações para serviços de saúde: medidas de prevenção e controle que devem ser adotadas durante a assistência aos casos suspeitos ou confirmados de infecção pelo novo coronavírus (2019-nCoV). Agência Nacional de Vigilância Sanitária (ANVISA). http://portal.anvisa.gov.br/documents/33852/271858/Nota+T\%C3\%A9cnica+n+04-2020+GVIMS-GGTES-ANVISA/ab598660-3de4-4f14-

8e6fb9341c196b28.

Arnemann, C. T., Lavich, C. R. P., Terra, M. G., Mello, A. L. \& Raddatz, M. (2018). Educação em saúde e educação permanente: ações que integram o processo educativo da enfermagem. Rev. baiana enferm. 32, e 24719. 10.18471/rbe. v32.24719

Brasil, Conselho Federal de Enfermagem (BR). (2020). Enfermagem em números. http://www.cofen.gov.br/enfermagem-em-numeros.

Brasil, Ministério da Saúde. Secretaria de Vigilância em Saúde. (2020). Boletim Epidemiológico nº 01 Secretaria de Vigilância em Saúde SVS/MS-COE. http://portalarquivos2.saude.gov.br/images/pdf/2020/janeiro/28/Boletim-epidemiologicoSVS-28jan20.pdf.

Brasil, Ministério da Saúde. Secretaria de Vigilância em Saúde. (2021). Painel Coronavírus; Síntese de casos, óbitos, incidência e mortalidade. https://covid.saude.gov.br/.

Cardoso, R. F., Alberto, D. S., Maués, S. C. C., Silva, S. R. M., Abreu, A. C., Coelho, J. S. M., et al. (2021). COVID-19: Um desafio epidemiológico. Research, Society and Development, 10(7), e32110716313. 10.33448/rsd-v10i7.16313. https://rsdjournal.org/index.php/rsd/art icle/view/16313.

Centers for Disease Control and Prevention (CDC) (2020). Severe out comesam ong patients with Coronavirus Disease 2019 (COVID-19): United States. Morbidity and Mortality Weekly Report, 69(12), e 343-346. https://doi.org/10.15585/mmwr.mm6912e2.

Conselho Federal de Enfermagem (COFEN) (2020). Enfermagem em Números. http://www.cofen.gov.br/enfermagem-em-numeros.

Conselho Federal de Enfermagem (COFEN) (2020). Vacinação reduz mortes em profissionais da saúde pela Covid-19. Conselho Federal de Enfermagem. http://www.cofen.gov.br/vacinacao-reduz-mortes-em-profissionais-da-saude-pela-covid-19_88839.html.

Cunha, C. M., Almeida Neto, O. P. Stackfleth, R. (2016). Principais métodos de avaliação psicométrica da confiabilidade de instrumentos de medida. Rev. Aten. Saúde, São Caetano do Sul, 14(49), 98-103, 10.13037/rbcs.vol14n49.3671

Galindo Neto, N. M., Sá, G. G. M., Barbosa, L. U., Pereira, J. C. N., Henriques, A. H. B., Barros L. P. M. (2020). Covid-19 and digital technology: mobile application savailable for download in smartphones. Texto contexto - enferm., 29, e20200150. http://www.revenf.bvs.br/scielo.php?scrip $\mathrm{t}=$ sci_arttext\&pid=S0104-07072020000100203\&lng=pt\&nrm=iso.

Garcia, G. P., Luis, P., Barbosa, P., Silva, A. Souza, A., Drin, F. et al. (2021). Utilização de equipamentos de proteção individual para atendimento de pacientes com covid-19: revisão de escopo. Rev Gaúcha Enferm. 4, e20200150. https://doi.org/10.1590/1983- 1447.2021.20200150. 
Gottems, L. B. D., Carvalho, E. M. P., Guilhem, D., Pires, M. R. G. M. (2018). Good practices in normal childbirth: reliability analysis of an instrument by Cronbach's Alpha. Rev. Latino-Am. Enfermagem. 26, e3000. http://dx.doi.org/10.1590/1518-8345.2234.3000.

Knechtel, M. R. (2014). Metodologia da pesquisa em educação: uma abordagem teórica-prática dialogada. Curitiba: Inter saberes. https://dtcom.com.br/wayco/temas/section_2/pesquisa_qualitativa_e_quantitativa/sections/pdf/THEME4285.pdf.

Landis, J. R. \& Koch, G. G. (2020). The measure mentof observer agreement for categorical data. Biometrics, 33(1), 159-174, 1977.

Oliveira, W. K., Duarte, E., França, G. V. A., Garcia, L. P. (2020). Como o Brasil pode deter a COVID-19. Epidemiologia e Serviços de Saúde, 29, 1-9. http://dx.doi.org/10.5123/s1679-49742020000200023.

Organização Pan-Americana da Saúde (OPAS) (2021). Covid-19. Declaração conjunta sobre o novo coronavírus e cães e gatos. https://www.paho.org/pt/documentos/covid-19-comunicado-conjunto-sobre-nuevo-coronavirus-perros-gatos

Organização Mundial da Saúde (OMS) (2020). Coronavirus disease (COVID-19). https://www.who.int/emergencies/diseases/novel-coronavirus2019/question-and-answers-hub/q-a-detail/q-a-coronaviruses\#: :text=symptoms.

Organização Mundial da Saúde (OMS) (2021). Boletins diários acerca do Covid-19. https://www.paho.org/pt/Brasil.

Ribeiro, A. P., Oliveira, G. L., Silva, L. S. \& Souza, E. R. (2020). Saúde e segurança de profissionais de saúde no atendimento a pacientes no contexto da pandemia de Covid-19: revisão de literatura. Rev. bras. saúde ocup., 45.

Secretaria de Estado de Saúde de Mato Grosso (SES-MT) (2020). Boletins diários do coronavírus. Secretaria de Estado de Saúde de Mato Grosso. http://www5.sefaz.mt.gov.br/noticias?p_p_id=101\&p_p_lifecycle=0\&p_p_state =maximized\&p_p_mode=view\&_101_struts_action=\%2Fasset_publisher\%2F view_content\&_101_assetEntryId=15483874\&_101_type=document\&redirect=http\%3A\%2F\%2Fwww5.sefaz.mt.gov.br\%2Fnoticias\%3Fp_p_id\%3D3\%26p_ p_lifecycle\%3D0\%26p_p_state\%3Dmaximized\%26p_p_mode\%3Dview\%26_3_groupId\%3D0\%26_3_groupId\%3D0\%26_3_keywords\%3Dcovid\%26_3_key words\%3Dcovid\%26_3_struts_action\%3D\%252Fsearch\%252Fsearch\%26_3_struts_action\%3D\%252Fsearch\%252Fsearch\%26_3_redirect\%3D\%252F-

\%252F13984781-governo-anuncia-novas-medidas-para-conter-coronavirus-em-mato-grosso\%26_3_redirect\%3D\%252F-\%252F13984781-governo-anuncianovas-medidas-para-conter-coronavirus-em-mato-grosso.

Secretaria de Estado de Saúde de Mato Grosso (SES-MT) (2021). Boletins diários do coronavírus. http://www5.sefaz.mt.gov.br/noticias?p_p_id=101\&p_p_lifecycle=0\&p_p_state=maximized\&p_p_mode=view\&_101_struts_action=\%2Fasset_publisher\%2F view_content\&_101_assetEntryId=15483874\&_101_type=document\&redirect=http\%3A\%2F\%2Fwww5.sefaz.mt.gov.br\%2Fnoticias\%3Fp_p_id\%3D3\%26p_ p_lifecycle\%3D0\%26p_p_state\%3Dmaximized\%26p_p_mode\%3Dview\%26_3_groupId\%3D0\%26_3_groupId\%3D0\%26_3_keywords\%3Dcovid\%26_3_key words\%3Dcovid\%26_3 struts_action\%3D\%252Fsearch\%252Fsearch\%26 3 struts action\%3D\%252Fsearch\%252Fsearch\%26 3 redirect\%3D\%252F\%252F13984781-governo-anuncia-novas-medidas-para-conter-coronavirus-em-mato-grosso\%26_3_redirect\%3D\%252F-\%252F13984781-governo-anuncianovas-medidas-para-conter-coronavirus-em-mato-grosso.

Silva, E., Marcia, A. G., Jairo, S. S., Mariza, G., Isaias, S. G., Higor, J. N. S et al. (2021). Condutas sanitárias no enfrentamento da COVID-19. Research, Society and Development, [S. 1.], v. 10, n. 6, p. e42210615448. DOI: 10.33448/rsd-v10i6.15448. https://rsdjournal.org/index.php/rsd/article/view/15448.

Silva, S. L. (2020). Enfermagem na atenção básica no contexto da COVID-19 / Organização Sheila Saint-Clair da Silva Teodósio, Suderlan Sabino Leandro. Brasília, DF: ABen/DEAB. http://www.abennacional.org.br/site/wp-content/uploads/2020/09/E-BOOK-ATENCAO-BASICA.pdf.

Souza, L. P. S, \& Souza, A. G. (2020). Enfermagem brasileira na linha de frente contra o novo Coronavírus: quem cuidará de quem cuida? J. Nurs. Health. v.10, e20104005. http://docs.bvsalud.org/biblioref/2020/05/1095606/1-enfermagem-brasileira-na-linha-de-frente-contra-o-novo-coron_ygPksqt.pdf.

World Health Organization (WHO) (2020). Coronavirus disease 2019 (COVID-19): situation report .http://www.who.int/docs/defaultsource/coronaviruse/situation-reports/20200407-sitrep-78-covid-19.pdf?sfvrsn=bc43e1b_2. 